\title{
Association of rheumatoid factor and anti-cyclic citrullinated peptide positivity, but not carriage of shared epitope or PTPN22 susceptibility variants, with anti-tumour necrosis factor response in rheumatoid arthritis
}

\author{
C Potter, ${ }^{1}$ K L Hyrich, ${ }^{1}$ A Tracey, ${ }^{1}$ M Lunt, ${ }^{1}$ D Plant, ${ }^{1}$ D P M Symmons, ${ }^{1}$ W Thomson, ${ }^{1}$ \\ J Worthington, ${ }^{1}$ P Emery, ${ }^{2}$ A W Morgan, ${ }^{2}$ A G Wilson, ${ }^{3}$ J Isaacs, ${ }^{4}$ A Barton, ${ }^{1}$ \\ and BRAGGSS
}

\begin{abstract}
${ }^{1}$ Arthritis Research Campaign Epidemiology Unit, University of Manchester, Manchester, UK;

${ }^{2}$ Leeds Institute of Molecular Medicine, Section of

Musculoskeletal Disease, University of Leeds, Leeds, UK;

${ }^{3}$ Section of Musculoskeletal

Sciences, University of Sheffield, Sheffield, UK; ${ }^{4}$ Musculoskeletal Research Group, Institute of Cellular Medicine, Newcastle University, Newcastle-uponTyne, UK
\end{abstract}

Correspondence to:

A Barton, ARC-EU, Stopford

Building, University of

Manchester, Oxford Road

Manchester M13 9PT, UK; anne.

barton@manchester.ac.uk

A list of members of the Biologics in Rheumatoid Arthritis Genetics and Genomics Study Syndicate (BRAGGSS) is given in the index

Accepted 9 March 2008 Published Online First 28 March 2008

\section{ABSTRACT}

Objective: To determine whether rheumatoid factor (RF), anti-cyclic citrullinated peptide (CCP) antibodies, or carriage of shared epitope (SE) and PTPN22 genetic susceptibility variants predict response to therapy in patients with rheumatoid arthritis (RA) treated with antitumour necrosis factor (TNF) agents.

Methods: UK-wide multicentre collaborations were established to recruit a large cohort of patients treated with anti-TNF drugs for RA. Serum RF, anti-CCP antibody and SE status were determined using commercially available kits. PTPN22 R620W genotyping was performed by Sequenom MassArray. Linear regression analyses were performed to investigate the role of these four factors in predicting response to treatment by 6 months, defined as the absolute change in 28-joint Disease Activity Score (DAS28).

Results: Of the 642 patients analysed, $46 \%$ received infliximab, $43 \%$ etanercept and $11 \%$ adalimumab. In all, $89 \%$ and $82 \%$ of patients were RF and anti-CCP positive, respectively. Patients that were RF negative had a 0.48 (95\% Cl 0.08 to 0.87) greater mean improvement in DAS28 compared to patients that were RF positive. A better response was also seen among patients that were anti-CCP negative. No association was demonstrated between drug response and SE or PTPN22 620W carriage.

Conclusion: The presence of RF or anti-CCP antibodies was associated with a reduced response to anti-TNF drugs. However, these antibodies only account for a small proportion of the variance in treatment response. It is likely that genetic factors will contribute to treatment response, but these do not include the well established RA susceptibility loci, SE and PTPN22.

To date, three anti-tumour necrosis factor (TNF) biological agents have been approved for the treatment of rheumatoid arthritis (RA), namely etanercept. ${ }^{1}$ Collectively these drugs have become one of the most effective methods of treating RA, with nearly half of all treated patients achieving an American College of Rheumatology 20\% (ACR20) improvement level or higher. However, there is still a substantial proportion of patients who show partial or no response to anti-TNF therapy. With treatment limited by expensive annual costs in many countries, a number of studies have investigated predictors of response in treated patients. ${ }^{2-4}$ For example, analyses in a large-scale longitudinal observational study cohort identified lower baseline health assessment questionnaire (HAQ) scores and concurrent treatment with disease-modifying antirheumatic drugs (DMARDs) as predictors of greater response rates, although the latter was only significant in the group of patients treated with etanercept. ${ }^{4}$

Serological and genetic factors are also likely to contribute towards drug response. Several small studies (sample sizes $<130$ ) have investigated the utility of autoantibodies, including rheumatoid factor (RF) and anti-cyclic citrullinated peptide (anti-CCP), for predicting response to treatment with biological agents but results have been inconsistent. ${ }^{2} 56$ Similarly, studies have investigated the role of genetic polymorphisms in the genes encoding TNF, ${ }^{7-12}$ interleukin (IL) $1 \beta$ and the IL1-receptor antagonist, ${ }^{11}{ }^{13}$ IL10, ${ }^{13}{ }^{14}$ transforming growth factor (TGF) $\beta 1^{13}$ and Fc $\gamma$ RIIIA $^{15} 16$ with inconsistent findings. In particular, a significant association was demonstrated between carriage of the shared epitope (SE) and response to etanercept in a cohort of 200 patients in the USA ${ }^{12}$ but was not replicated in a smaller study of 123 patients from Sweden. ${ }^{13}$ Furthermore, no association of SE status with response to infliximab treatment was observed in two European populations (78 patients from Spain and 198 patients from France). ${ }^{11} 17$ However, most of these studies were hindered by small sample sizes resulting in limited power to detect modest effects. In this study we established a UK-wide multicentre collaboration to recruit a large cohort of patients treated with anti-TNF agents and tested the hypothesis that confirmed RA susceptibility factors, namely RF, anti-CCP, SE and PTPN22 620W, are associated with clinical response in patients treated with anti-TNF.

\section{METHODS}

\section{Patient selection}

UK-wide multicentre collaborations were established to recruit patients treated with anti-TNF drugs for RA. Eligible patients from each centre were subsequently identified from the British Society of Rheumatology's (BSR) Biologics Register (BR). ${ }^{18}$ This register compiles extensive 
clinical information on patients starting treatment with a biological agent and follows them prospectively, on a 6-monthly basis for 5 years, in order to monitor and determine the incidence of potential short and long term hazards. The following criteria were used for the selection of patients for the current study: (1) currently actively participating in the BSRBR long-term safety study, (2) doctor-confirmed diagnosis of RA, (3) currently or have been treated with one of the three anti-TNF biological agents, (4) European Caucasian descent and (5) reached 6 months of follow-up. Patients who stopped treatment temporarily during the first 6 months of therapy were excluded from selection. Similarly, patients who discontinued therapy prior to the 6-month follow-up for any reason other than inefficacy were excluded from selection.

\section{Patient recruitment and sample collection}

Eligible patients from each collaborating centre were invited to take part in the study. Additional blood samples were obtained from consenting patients when they required a blood test as part of routine care. The additional blood samples and signed consent forms were posted to the Arthritis Research Campaign (arc) Epidemiology Unit for processing and storage. For the majority of patients, two samples of blood were taken: one for serum and one for DNA extraction. DNA was isolated using a standard phenol/chloroform extraction method. Serum and DNA samples were stored at $-80^{\circ} \mathrm{C}$. UK Central Office of Research Ethics Committees (COREC) approval (04/O1403/37) was obtained for the study.

\section{Clinical information}

Clinical and demographic data held on the BSRBR database was extracted, with the consultants' permission, and compiled for each consenting patient. Disease activity was measured using the 28 -joint count disease activity score (DAS28). ${ }^{19}$

\section{Immunogenetics}

Serum RF and anti-CCP antibody titre were measured using commercially available kits (RF-PAIA Immunoturbidimetric Assay for rheumatoid factor, Diastat Anti-CCP Kit (AxisShield Diagnostics, Dundee, UK)). Patients with titres $\geqslant 40 \mathrm{U} /$ $\mu \mathrm{l}$ and $\geqslant 5 \mathrm{U} / \mu \mathrm{l}$ were defined as positive for RF and anti-CCP antibodies, respectively. HLA-DRB1 typing was performed using commercially available kits (Dynal RELI SSO HLADRB1 Typing Kit (Dynal Biotech, Wirral, UK)). The SE was defined as the presence of any of the following alleles: human leukocyte antigen (HLA)-DRB1*0101, ${ }^{*} 0102,{ }^{*} 0104,{ }^{*} 0401$, ${ }^{*} 0404,{ }^{*} 0405,{ }^{*} 0408$ or ${ }^{*} 1001$. In addition, PTPN22 R620W $(1858 \mathrm{C} / \mathrm{T})$ genotyping was performed using mass spectrometry (Sequenom, Cambridge, UK) as recommended by the manufacturer.

\footnotetext{
Analysis

The primary outcome measure was absolute change in DAS28 between baseline and 6 months. Linear regression analyses were performed to investigate association between change in DAS28 and RF, anti-CCP status, SE and PTPN22*620W carriage. For the purposes of this analysis, the recorded 6-month DAS28 score was used whether patients had discontinued therapy or not. Analyses were adjusted for baseline DAS28, baseline HAO score, administration of concurrent DMARDs and gender, as these factors have previously been shown to be significant independent predictors of response in the BSRBR cohort as a whole and were also associated in the current cohort (see supplementary
}

material). ${ }^{4}$ Analyses were repeated excluding any patients with previous exposure to a biological drug, whether or not it was the same agent. In addition, interaction analyses were performed to determine whether any observed effects were similar across the two major drug types, namely etanercept and infliximab. Patients treated with adalimumab were excluded from this latter analysis due to the small numbers in this subgroup. Finally, the European League Against Rheumatism (EULAR) improvement criteria was assessed as a secondary outcome measure using logistic regression analyses and applying the same model as described above. ${ }^{20}$ Power calculations were performed using Quanto (http://hydra.usc.edu/gxe). ${ }^{21}$

\section{RESULTS}

\section{Patient recruitment}

Collaborations were established with 20 rheumatology centres across the UK from which 1485 patients receiving anti-TNF therapy for RA satisfied the study inclusion criteria. Of these, 1292 responded to the invitation letter (87\%) with 1195 patients willing to take part (80\%). DNA samples were extracted and available for the first set of 642 patients to be recruited, which were utilised in the current analysis.

\section{Baseline characteristics and immunogenetics}

Baseline characteristics for the group of 642 patients are presented in table 1. Clinical and demographic measures were comparable to those previously reported across the BSRBR dataset as a whole, indicating that this cohort was representative of the larger anti-TNF-treated RA population in the UK. ${ }^{22}$

Genotyping of the PTPN22 R620W (C1858T) polymorphism and SE was successfully performed in $96 \%$ and $83 \%$ of patients, respectively (table 2). Given the frequencies, there was more than $90 \%$ power to detect a difference of $\geqslant 0.6 \mathrm{U}$ in the absolute change in DAS28 following 6 months of therapy at the $5 \%$ significance level, for PTPN22 and SE carriage in the current cohort. This level of improvement reflects the difference between non- and moderate-responders, based on the EULAR criteria. Autoantibody titres were available for $81 \%$ of patients (table 2), providing $77 \%$ and $91 \%$ power to detect the same effect described above for RF and anti-CCP positivity, respectively.

\section{Predictors of response}

By the first 6 months follow-up, $10 \%$ had discontinued treatment due to inefficacy while $90 \%$ continued anti-TNF therapy. Based on the EULAR improvement criteria, $21 \%$ of patients were non-responders, $52 \%$ moderate responders and $27 \%$ good responders. The mean change in DAS28 was an improvement of 2.5 points and this is consistent with data from the BSRBR as a whole. ${ }^{22}$ Baseline and absolute change in DAS28 values were normally distributed across the patient population.

Linear regression analyses were first performed to investigate association between drug response at 6 months, defined as the absolute change in DAS28, and the baseline factors listed in table 1. Of these, baseline DAS28, baseline HAO score, concurrent DMARD therapy and gender were significantly associated with drug response $\left(p \leqslant 6.2 \times 10^{-3}\right.$; see supplementary material). These findings were expected as associations to these factors have been previously reported in the BSRBR data, from which the current cohort was recruited. ${ }^{4}$ Thus, in all analyses, adjustments were made for these baseline factors.

Linear regression analyses were subsequently performed to investigate association of drug response with RF, anti-CCP, SE 
Table 1 Baseline characteristics

\begin{tabular}{lcccc}
\hline Baseline characteristics & Etanercept & Infliximab & Adalimumab & Combined \\
\hline Number of cases & $278(43)$ & $296(46)$ & $68(11)$ & 642 \\
Age, years* & $57(11)$ & $58(11)$ & $59(12)$ & $57(11)$ \\
No. female & $223(80)$ & $228(77)$ & $51(75)$ & $502(78)$ \\
Current smokers & $56(20)$ & $51(17)$ & $6(9)$ & $113(18)$ \\
Ever smoked & $163(59)$ & $168(57)$ & $35(51)$ & $366(57)$ \\
Disease duration, years* & $13(9)$ & $15(10)$ & $13(10)$ & $14(10)$ \\
DAS28* & $6.7(1)$ & $6.7(1)$ & $6.5(1)$ & $6.7(1)$ \\
HAO* & $2(0.6)$ & $2(0.6)$ & $2(0.5)$ & $2(0.6)$ \\
Concurrent DMARD(s) & $152(55)$ & $277(94)$ & $38(56)$ & $467(73)$ \\
Concurrent steroids & $105(38)$ & $135(46)$ & $24(35)$ & $264(41)$ \\
Previous biological & $21(8)$ & $10(3)$ & $3(4)$ & $34(5)$ \\
\hline
\end{tabular}

*Values are mean (SD). All other values are $\mathrm{n}(\%)$

DAS28, 28-joint disease activity score; DMARD, disease-modifying antirheumatic drug; HAQ, Health Assessment Questionnaire.

and PTPN22*620W status (table 3). Compared to patients negative for RF, patients positive for RF demonstrated significantly less improvement in their DAS28 values following anti-TNF therapy (coefficient $-0.48,95 \%$ CI -0.87 to -0.08 , $p=0.018$ ) (table 3 ). Similarly, patients positive for anti-CCP antibodies demonstrated significantly less improvement in DAS28 compared to anti-CCP negative subjects (coefficient $-0.39,95 \%$ CI -0.71 to $-0.07, p=0.017$ ) (table 3 ). Repeating the analysis after exclusion of patients with a previous exposure to a biological agent did not alter these conclusions (table 3). By contrast, the difference in anti-TNF treatment response between patients that were autoantibody positive and negative was not statistically significantly different when assessed using logistic regression analyses with the EULAR response criteria as the outcome measure, although a trend was observed (see supplementary material). This highlights the greater power of continuous compared to categorical data for such analyses. No association was demonstrated between drug response and either SE or PTPN22*620W carriage, under any model tested $(\mathrm{p}>0.05)$ (table 3 and supplementary material).

The effects of RF and anti-CCP antibodies were investigated further by performing multivariate linear regression combining both antibodies, together with previously known predictors (baseline HAQ, concurrent DMARD therapy and gender). Being positive for RF and anti-CCP did not better predict response to anti-TNF therapy (RF only: $\mathrm{R}^{2}=0.17$, anti-CCP only: $\mathrm{R}^{2}=0.17$, RF plus anti-CCP: $\left.R^{2}=0.17\right)$. Furthermore, there was no interaction between these two factors and their association with drug response (RF*anti-CCP: $\mathrm{R}^{2}=0.18, \quad \mathrm{p}=0.16$ ). However, as the majority of patients were positive for both antibodies, these analyses may be underpowered.

Finally, in order to investigate whether the predictive effects of RF and anti-CCP antibodies were equal for etanercept and infliximab response, linear regression was performed including the interaction between drug type and autoantibody status. These analyses suggested that, although the effects of RF and anti-CCP antibodies appeared restricted to patients treated with infliximab, the effects were not statistically significantly different between the two major drug types (table 4).

\section{DISCUSSION}

The introduction of anti-TNF biological agents has transformed the management of RA. However, a substantial proportion of treated patients still demonstrate partial or no response to these therapies. Previous studies have suggested that the effect of clinical factors alone in predicting response is relatively modest. ${ }^{2-4}$ Hence, in the current study, we have focused on genetic and serological markers. In keeping with previous reports, we have shown that the presence of RF and anti-CCP antibodies is associated with a significantly reduced improvement in the DAS28 score following 6 months of anti-TNF therapy. No associations were demonstrated between drug response and carriage of risk alleles for either of the other two well established RA susceptibility factors, SE or PTPN22.

There are a number of methodological limitations to the study, which require discussion. Firstly, although the current study design may inform predictions of how patients receiving anti-TNF therapies will respond to those treatments, the lack of a control group of patients with RA that were not anti-TNF treated means that the study cannot inform the debate about whether a patient will respond better to therapy with an antiTNF rather than a DMARD treatment.

Secondly, response measures were assessed at 6 rather than 3 months, when clinical decisions regarding the continuation of therapy are usually made. Consequently, $\sim 10 \%$ of patients had discontinued therapy due to inefficacy prior to the 6-month follow-up and some will have commenced alternative treatment to which they may have responded. Hence, the DAS28 at 6 months may not be a true reflection of the DAS28 when the drug was discontinued. However, this subgroup of patients generally remained non-responders at 6 months despite possibly receiving alternative drugs (mean DAS28 improvement at 6 months: 0.8 compared to 2.7 across the remainder of the cohort). As the study aims to identify predictors of response by

Table 2 Rheumatoid factor (RF), anti-cyclic citrullinated peptide (CCP), shared epitope (SE) and PTPN22 status

\begin{tabular}{lllll}
\hline & Etanercept & Infliximab & Adalimumab & Combined \\
\hline RF positive & $219 / 241(91)$ & $189 / 218(87)$ & $54 / 62(87)$ & $462 / 521(89)$ \\
Anti-CCP positive & $206 / 241(86)$ & $177 / 218(81)$ & $42 / 62(68)$ & $425 / 521(82)$ \\
SE carriage & $184 / 225(82)$ & $208 / 261(80)$ & $40 / 49(82)$ & $432 / 535(81)$ \\
PTPN22 carriage & $78 / 268(29)$ & $93 / 287(33)$ & $17 / 64(27)$ & $188 / 619(30)$ \\
\hline
\end{tabular}

Values are $\mathrm{n}$ of positive/total available (\% positive). 
Table 3 Linear regression for rheumatoid factor (RF), anti-cyclic citrullinated peptide (CCP), shared epitope (SE) and PTPN22

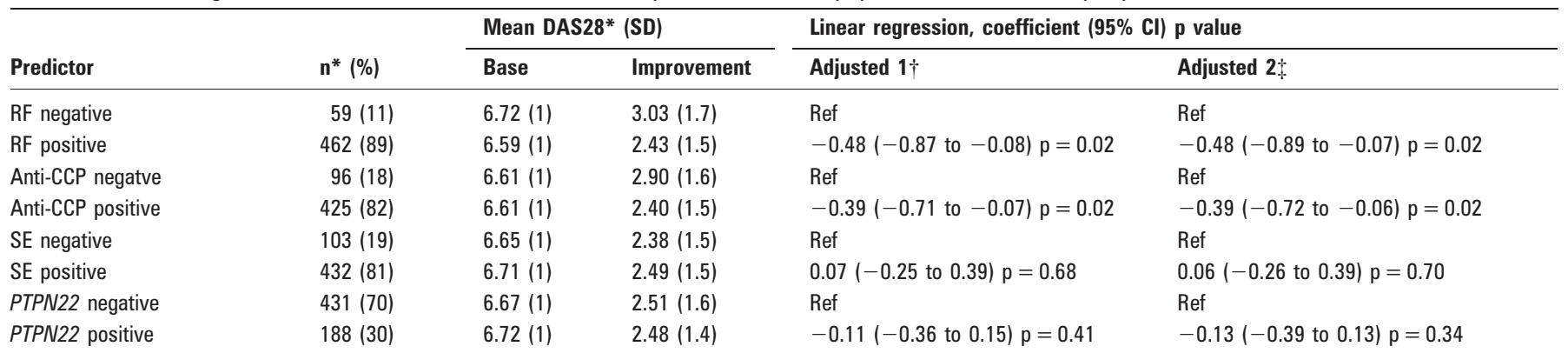

*Figures represent those across the complete subgroup of 642 patients. †lnitial analyses were performed across the entire cohort, adjusting for baseline DAS28, HAQ, concurrent DMARD therapy and gender. $\$$ Subsequent analyses excluded patients with previous exposure to a biological agent.

DAS28, 28-joint Disease Activity Score; DMARD, disease-modifying antirheumatic drug; HAQ, Health Assessment Questionnaire; Ref, reference group.

6 months rather than predictors of response only in those who remain on treatment, these patients were included in the analysis although we recognise that this may have resulted in underestimations of observed effects.

Thirdly, as one of the requirements for prescribing anti-TNF agents in the UK includes failure of at least two previous DMARDs, the patients recruited have severe, long-standing RA with a mean duration of 14 years. As discussed by Hyrich et al, patients with more severe disease as a result of irreversible joint damage may be less likely to respond to treatment. ${ }^{4}$ In order to account for this, analyses were repeated adjusting for disease duration, but this did not change the overall conclusions (see supplementary material).

Lastly, the serology was measured cross-sectionally at the time of sample collection, which may have been some time after commencement of treatment. Previous studies have shown that, although titres are affected by treatment, status generally is not. ${ }^{23}$ Based on records held on the BSRBR, antibody status changed from positive to negative during anti-TNF treatment in less than $3 \%$ of patients included in the current analyses. Hence, in all the analyses, autoantibody status rather than titre has been used. It should also be noted that the proportion of patients that were RF positive in the current study is higher than that reported previously for the BSRBR cohort as a whole ( $89 \%$ vs $72 \%$, respectively). ${ }^{4}$ This is most likely to be due to differences in data collection methods: the BSRBR study relies on information being provided by the contributing doctors whereas, for the purposes of the current study, RF was remeasured in all patients for whom a serum sample was available.
Conversely, our study has several advantages over previous investigations. Importantly, the use of the BSRBR to identify suitable patients has meant that the subgroup studied is comparable to the BSRBR in its entirety. As, until relatively recently, almost all patients receiving an anti-TNF drug in the UK for RA were included on this register, the cohort studied is likely to reflect the characteristics of patients treated with anti-TNF as a whole, at least in the UK. Furthermore, a wealth of clinical and demographic data had already been collected, creating a well characterised cohort. In addition, this is a large cohort, allowing robust inferences to be drawn. Finally, the use of the DAS28 measure rather than the EULAR response criteria enhances the power of the study to detect association with genetic predictors of response in patients with RA treated with anti-TNF.

As no correction for multiple testing was applied in the current analyses, these results will require validation in similarsized cohorts. Nonetheless, the findings support those of smaller studies in which similar trends between drug response and baseline RF and anti-CCP antibody titres have been demonstrated. $^{236}$ As discussed by Mewar et al, RF and anti-CCP antibodies are independent markers of disease severity for RA. ${ }^{24}$ Thus the present findings could be interpreted as showing that those patients with the most severe disease are least likely to respond to these therapies. Indeed, there is some evidence to support this hypothesis, as HAO score, a measure of disability, was also significantly associated with response. However, RF and anti-CCP antibody status remained significant predictors of response even after accounting for markers of severity such as $\mathrm{HAO}$ and disease duration.

Table 4 Linear regression of rheumatoid factor (RF) and anti-cyclic citrullinated peptide (CCP), stratifying for anti-tumour necrosis factor (TNF) agents

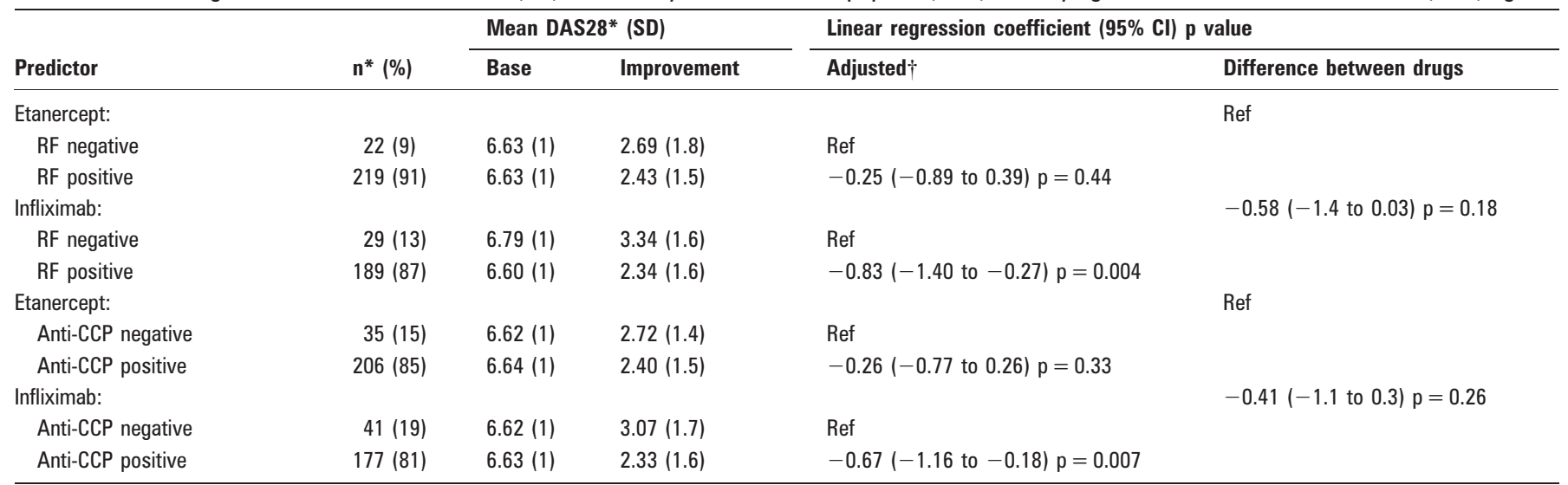

*Figures represent those across the complete subgroup of 642 patients. †Analyses adjusted for baseline DAS28, HAQ, concurrent DMARD therapy and gender. DAS28, 28-joint Disease Activity Score; DMARD, disease-modifying antirheumatic drug; HAQ, Health Assessment Questionnaire; Ref, reference group. 
It is salient to note that combining information on clinical markers of anti-TNF treatment response previously identified, (concurrent DMARD therapy, baseline $\mathrm{HAO}$ and gender) ${ }^{2-4}$ with RF and anti-CCP antibody status data still only accounts for a small proportion of the variance in drug response $\left(R^{2}=17 \%\right)$ and would not be useful in the clinical setting. We hypothesise that, in addition to these clinical and serological factors, genetic factors will play a role and the challenge now is to identify these. No association was observed between treatment response and carriage of the RA susceptibility allele of the PTPN22 gene and, in keeping with most previous studies, no association of treatment response was observed with SE carriage, a well established RA severity and susceptibility locus. Several novel RA susceptibility loci have recently been reported (eg, OLIG3/TNFAIP3, TRAF1/C5 and STAT4), which may also warrant investigation. ${ }^{25-28}$ However, genes contributing to disease susceptibility may be different to those that determine response to treatment.

In summary, the presence of RF or anti-CCP antibodies was associated with a reduced response to anti-TNF drugs in patients with RA treated with anti-TNF. However, the presence of these antibodies only accounts for a small proportion of the variance in treatment response. It is likely that genetic factors will contribute to determining the response to treatment with these agents but do not include the well established RA susceptibility loci, SE or PTPN22.

Acknowledgements: We would like to thank Hannah Donovan, Paul Gilbert and Catriona McWhirter for performing DNA extractions and HLA typing, Sarah Netherwood and Suzanne Pilkington for performing the serological tests and Mark Lay for help with the databases. We thank the Arthritis Research Campaign for their support.

\section{REFERENCES}

1. Bain B, Brazil M. Adalimumab. Nat Rev Drug Discov 2003;2:693-4.

2. Bobbio-Pallavicini F, Caporali R, Alpini C, Avalle S, Epis 0, Klersy C, et al. High IgA rheumatoid factor levels are associated with poor clinical response to tumour necrosis factor $\alpha$ inhibitors in rheumatoid arthritis. Ann Rheum Dis 2007:66:302-7.

3. Braun-Moscovici Y, Markovits D, Zinder O, Schapira D, Rozin A, Ehrenburg M, et al. Anti-cyclic citrullinated protein antibodies as a predictor of response to anti-tumor necrosis factor- $\alpha$ therapy in patients with rheumatoid arthritis. J Rheumatol 2006;33:497-500.

4. Hyrich KL, Watson KD, Silman AJ, Symmons DP. Predictors of response to antiTNF- $\alpha$ therapy among patients with rheumatoid arthritis: results from the British Society for Rheumatology Biologics Register. Rheumatology (Oxford) 2006:45:1558-65.

5. Morozzi G, Fabbroni M, Bellisai F, Cucini S, Simpatico A, Galeazzi M. Low serum level of COMP, a cartilage turnover marker, predicts rapid and high ACR70 response to adalimumab therapy in rheumatoid arthritis. Clin Rheumatol 2007;26:1335-8.

6. Alessandri C, Bombardieri M, Papa N, Cinquini M, Magrini L, Tincani A, et al. Decrease of anti-cyclic citrullinated peptide antibodies and rheumatoid factor following anti-TNF $\alpha$ therapy (infliximab) in rheumatoid arthritis is associated with clinical improvement. Ann Rheum Dis 2004;63:1218-21.

7. Mugnier B, Balandraud N, Darque A, Roudier C, Roudier J, Reviron D. Polymorphism at position -308 of the tumor necrosis factor $\alpha$ gene influences outcome of infliximab therapy in rheumatoid arthritis. Arthritis Rheum 2003;48:1849-52.

8. Balog A, Klausz G, Gal J, Molnar T, Nagy F, Ocsovszky I, et al. Investigation of the prognostic value of TNF- $\alpha$ gene polymorphism among patients treated with infliximab, and the effects of infliximab therapy on TNF- $\alpha$ production and apoptosis. Pathobiology 2004;71:274-80.

9. Fonseca JE, Carvalho T, Cruz M, Nero P, Sobral M, Mourao AF, et al. Polymorphism at position -308 of the tumour necrosis factor $\alpha$ gene and rheumatoid arthritis pharmacogenetics. Ann Rheum Dis 2005;64:793-4.

10. Seitz M, Wirthmuller U, Moller B, Villiger PM. The -308 tumour necrosis factor$\alpha$ gene polymorphism predicts therapeutic response to TNF $\alpha$-blockers in rheumatoid arthritis and spondyloarthritis patients. Rheumatology (Oxford) 2007; 46:93-6.

11. Marotte H, Pallot-Prades B, Grange L, Tebib J, Gaudin P, Alexandre C, et al. The shared epitope is a marker of severity associated with selection for, but not with response to, infliximab in a large rheumatoid arthritis population. Ann Rheum Dis 2006;65:342-7.
12. Criswell LA, Lum RF, Turner KN, Woehl B, Zhu Y, Wang J, et al. The influence of genetic variation in the HLA-DRB1 and LTA-TNF regions on the response to treatment of early rheumatoid arthritis with methotrexate or etanercept. Arthritis Rheum 2004:50:2750-6.

13. Padyukov L, Lampa J, Heimburger M, Ernestam S, Cederholm T, Lundkvist I, et al. Genetic markers for the efficacy of tumour necrosis factor blocking therapy in rheumatoid arthritis. Ann Rheum Dis 2003;62:526-9.

14. Schotte H, Schluter B, Drynda S, Willeke P, Tidow N, Assmann G, et al. Interleukin 10 promoter microsatellite polymorphisms are associated with response to long term treatment with etanercept in patients with rheumatoid arthritis. Ann Rheum Dis 2005;64:575-81.

15. Kastbom A, Bratt J, Ernestam S, Lampa J, Padyukov L, Soderkvist P, et al. Fc $\gamma$ receptor type IIIA genotype and response to tumor necrosis factor $\alpha$-blocking agents in patients with rheumatoid arthritis. Arthritis Rheum 2007;56:448-52.

16. Tutuncu Z, Kavanaugh A, Zvaifler N, Corr M, Deutsch R, Boyle D. Fc $\gamma$ receptor type IIIA polymorphisms influence treatment outcomes in patients with inflammatory arthritis treated with tumor necrosis factor $\alpha$-blocking agents. Arthritis Rheum 2005:52:2693-6.

17. Martinez A, Salido M, Bonilla G, Pascual-Salcedo D, Fernandez-Arquero M, de Miguel S, et al. Association of the major histocompatibility complex with response to infliximab therapy in rheumatoid arthritis patients. Arthritis Rheum 2004;50:1077-82.

18. Silman A, Symmons D, Scott DG, Griffiths I. British Society for Rheumatology Biologics Register. Ann Rheum Dis 2003;62(Suppl 2):iï28-9.

19. Prevoo ML, van't Hof MA, Kuper HH, van Leeuwen MA, van de Putte LB, van Riel PL. Modified disease activity scores that include twenty-eight-joint counts Development and validation in a prospective longitudinal study of patients with rheumatoid arthritis. Arthritis Rheum 1995;38:44-8.

20. van Gestel AM, Haagsma CJ, van Riel PL. Validation of rheumatoid arthritis improvement criteria that include simplified joint counts. Arthritis Rheum 1998;41:1845-50.

21. Gauderman WJ. Sample size requirements for matched case-control studies of gene-environment interaction. Stat Med 2002;21:35-50.

22. Hyrich K, Symmons D, Watson K, Silman A. Baseline comorbidity levels in biologic and standard DMARD treated patients with rheumatoid arthritis: results from a national patient register. Ann Rheum Dis 2006;65:895-8.

23. Atzeni F, Sarzi-Puttini P, Dell'Acqua D, de Portu S, Cecchini G, Cruini C, et al. Adalimumab clinical efficacy is associated with rheumatoid factor and anti-cyclic citrullinated peptide antibody titer reduction: a one-year prospective study. Arthritis Res Ther 2006;8:R3.

24. Mewar D, Coote A, Moore DJ, Marinou I, Keyworth J, Dickson MC, et al. Independent associations of anti-cyclic citrullinated peptide antibodies and rheumatoid factor with radiographic severity of rheumatoid arthritis. Arthritis Res Ther 2006:8:R128

25. Thomson W, Barton A, Ke X, Eyre S, Hinks A, Bowes J, et al. Rheumatoid arthritis association at 6q23. Nat Genet 2007;39:1431-3.

26. Kurreeman FA, Padyukov L, Marques RB, Schrodi SJ, Seddighzadeh M, StoekenRijsbergen $\mathrm{G}$, et al. A candidate gene approach identifies the TRAF1/C5 region as a risk factor for rheumatoid arthritis. PLoS Med 2007:4:e278.

27. Plenge RM, Seielstad M, Padyukov L, Lee AT, Remmers EF, Ding B, et al. TRAF1-C5 as a risk locus for rheumatoid arthritis--a genomewide study. N Engl J Med 2007;357:1199-209.

28. Remmers EF, Plenge RM, Lee AT, Graham RR, Hom G, Behrens TW, et al. STAT4 and the risk of rheumatoid arthritis and systemic lupus erythematosus. N Engl J Med 2007;357:977-86.

\section{APPENDIX}

Members of the Biologics in Rheumatoid Arthritis Genetics and Genomics Study Syndicate (BRAGGSS)

Cambridge University Hospitals NHS Foundation Trust (Dr A J Crisp, Professor J S H Gaston, Dr F C Hall, Dr B L Hazleman, Dr J R Jenner, Dr A Ostor, Dr B Silverman, Dr C Speed).

County Durham and Darlington Acute Hospitals NHS Trust (Dr D. Armstrong, Dr A J Chuck, Dr S Hailwood).

Derby Hospitals NHS Foundation Trust (Dr L J Badcock, Dr C M Deighton, Dr S C O'Reilly, Dr M R Regan, Dr Snaith, Dr G D Summers, Dr R A Williams).

Doncaster And Bassetlaw Hospitals NHS Foundation Trust (Dr J R Lambert, Dr R Stevens, Dr C Wilkinson).

Gateshead Health NHS Trust (Dr J Hamilton, Dr C R Heycock, Dr C A Kelly, Dr V Saravanan).

Hereford Hospitals NHS Trust (Dr D H Rees, Dr R B Williams).

Mid Staffordshire General Hospitals NHS Trust (Dr S V Chalam, Dr D Mulherin, Dr T Price, Dr T Sheeran).

Morecambe Bay Hospitals NHS Trust (Dr M Bukhari, Dr W N Dodds, Dr J P Halsey). Norfolk and Norwich University Hospital NHS Trust (Dr K Gaffney, Professor A J Macgregor, Dr T Marshall, Dr P Merry, Professor D G I Scott).

Pennine Acute Hospitals NHS Trust (Dr B Harrison, Dr M Pattrick, Dr H N Snowden). Peterborough and Stamford Hospitals NHS Foundation Trust (Dr N J Sheehan, Dr N E Williams).

Portsmouth Hospitals NHS Trust (Dr R G Hull, Dr J M Ledingham, Dr F Mccrae, Dr M R Shaban, Dr A L Thomas). 
Sandwell and West Birmingham Hospitals NHS Trust (Prof C D Buckley, Dr D C Carruthers, Dr R Elamanchi, Dr P C Gordon, Dr K A Grindulis, Dr F Khattak, Dr K Raza, Dr D.Situnayake).

Sheffield Teaching Hospitals NHS Trust (Dr M Akil, Dr R Amos, Dr D E Bax, Dr S Till, Dr G Wilson, Dr J Winfield).

South Tees Hospitals NHS Trust (Dr F Clarke, Dr J N Fordham, Dr M J Plant, Dr Tuck). St Helens and Knowsley Hospitals NHS Trust (Dr V E Abernethy, Dr J K Dawson, Dr M Lynch).

The Leeds Teaching Hospitals NHS Trust (Dr S Bingham, Professor P Emery, Dr A Morgan).
The Newcastle upon Tyne Hospitals NHS Trust (Dr F Birrell, Mr P Crook, Dr H E Foster Dr B Griffiths, Dr I D Griffiths, Dr M L Grove, Professor J D Isaacs, DR L Kay, Dr A Myers, Dr P N Platt, Dr D J Walker).

University Hospital Birmingham NHS Foundation Trust (Dr Bowman, Dr P Jobanputra, Dr R W Jubb, Dr E C Rankin).

University Hospital of North Staffordshire NHS Trust (Dr E H Carpenter, Dr P T Dawes, Dr A Hassell, Professor E M Hay, Dr S Kamath, Dr J Packham, Dr M F Shadforth). Whipps Cross University Hospital NHS Trust (Dr S P Donnelly, Dr D Doyle, Dr A Hakim, Dr J G Lanham).

\section{Access the latest content chosen by our Editors}

BMJ Journals editors select an article from each issue to be made free online immediately on publication. Other material is free after 12 months to non-subscribers. Access the Editor's Choice from the home page - or expand your horizons and see what the other BMJ Journals editors have chosen by following the links on any BMJ Journal home page. 


\section{Corrections}

The department of one of the authors who co-authored all of the below papers has found that the affiliations were not correct. The correct affiliations for Professor P Emery, for all of the below articles, are: ${ }^{1}$ Section of Musculoskeletal Disease, Leeds Institute of Molecular Medicine, University of Leeds; ${ }^{2}$ NIHR Leeds Musculoskeletal Biomedical Research Unit, Leeds Teaching Hospitals Trust, Leeds, UK.

1. Keystone E, Emery P, Peterfy CG, et al. Rituximab inhibits structural joint damage in patients with rheumatoid arthritis with an inadequate response to tumour necrosis factor inhibitor therapies. Ann Rheum Dis 2009;68:216-21.

2. Doward LC, McKenna SP, Whalley D, et al. The development of the L-OoL: a quality-of-life instrument specific to systemic lupus erythematosus. Ann Rheum Dis 2009;68:196-200.

3. Potter C, Hyrich KL, Tracey A, et al. Association of rheumatoid factor and anticyclic citrullinated peptide positivity, but not carriage of shared epitope or PTPN22 susceptibility variants, with anti-TNF response in RA. Ann Rheum Dis 2009;68:69-74.

4. Smolen JS, Han C, van der Heijde DM, et al.; Active-Controlled Study of Patients Receiving Infliximab for the Treatment of Rheumatoid Arthritis of Early Onset (ASPIRE) Study Group. Radiographic changes in rheumatoid arthritis patients attaining different disease activity states with methotrexate monotherapy and infliximab plus methotrexate: the impacts of remission and tumour necrosis factor blockade. Ann Rheum Dis 2009;68:823-7.

5. Buch MH, Boyle DL, Rosengren S, et al. Mode of action of abatacept in rheumatoid arthritis patients having failed tumour necrosis factor blockade: a histological, gene expression and dynamic magnetic resonance imaging pilot study. Ann Rheum Dis 2009;68:1220-7.

6. Emery P, Van Vollenhoven R, Ostergaard M, et al. Guidelines for initiation of antitumour necrosis factor therapy in rheumatoid arthritis: similarities and differences across Europe. Ann Rheum Dis 2009;68:456-9.

7. Bejarano V, Conaghan PG, Proudman SM, et al. Long-term efficacy and toxicity of ciclosporin A in combination with methotrexate in poor prognosis rheumatoid arthritis Ann Rheum Dis 2009;68:761-3.

8. Rudwaleit M, Landewé R, van der Heijde D, et al. The development of Assessment of SpondyloArthritis international Society classification criteria for axial spondyloarthritis (part I): classification of paper patients by expert opinion including uncertainty appraisal. Ann Rheum Dis 2009;68:770-6.

9. Bennett AN, Marzo-Ortega H, Emery P, et al.; Leeds Spondyloarthropathy Group. Diagnosing axial spondyloarthropathy. The new Assessment in SpondyloArthritis international Society criteria: MRI entering centre stage. Ann Rheum Dis 2009;68:765-7.

10. Marzo-Ortega H, McGonagle D, O'Connor P, et al. Baseline and 1-year magnetic resonance imaging of the sacroiliac joint and lumbar spine in very early inflammatory back pain. Relationship between symptoms, HLA-B27 and disease extent and persistence. Ann Rheum Dis 2009;68:1721-7.

11. Gilworth G, Emery P, Gossec L, et al. Adaptation and cross-cultural validation of the rheumatoid arthritis work instability scale (RA-WIS). Ann Rheum Dis 2009;68:1686-90.

12. Gilworth G, Emery P, Gossec L, et al. Adaptation and cross-cultural validation of the RA-WIS (Work Instability Scale). Ann Rheum Dis 2009;68:1686-90.

13. Jarrett SJ, Sivera F, Cawkwell LS, et al. MRI and clinical findings in patients with ankylosing spondylitis eligible for anti-tumour necrosis factor therapy after a short course of etoricoxib. Ann Rheum Dis 2009;68:1466-9.

14. Haugeberg G, Conaghan PG, Quinn $\mathrm{M}$, et al. Bone loss in patients with active early rheumatoid arthritis: infliximab and methotrexate compared with methotrexate treatment alone. Explorative analysis from a 12-month randomised, double-blind, placebo-controlled study. Ann Rheum Dis 2009;68:1898-901.

15. Genovese MC, Breedveld FC, Emery P, et al. Safety of biological therapies following rituximab treatment in rheumatoid arthritis patients. Ann Rheum Dis 2009;68:1894-7

16. Kekow J, Moots RJ, Emery P, et al. Patient-reported outcomes improve with etanercept plus methotrexate in active early rheumatoid arthritis and the improvement is strongly associated with remission: the COMET trial. Ann Rheum Dis 2010;69:222-5

17. Furst DE, Keystone EC, Fleischmann R, et al. Updated consensus statement on biological agents for the treatment of rheumatic diseases, 2009. Ann Rheum Dis 2010;69(Suppl 1):i2-29.

18. Freeston JE, Wakefield RJ, Conaghan PG, et al. A diagnostic algorithm for persistence of very early inflammatory arthritis: the utility of power Doppler ultrasound when added to conventional assessment tools. Ann Rheum Dis 2010;69:417-9.

19. Jones $\mathbf{E}$, Churchman SM, English A, et al. Mesenchymal stem cells in rheumatoid synovium: enumeration and functional assessment in relation to synovial inflammation level. Ann Rheum Dis 2010;69:450-7.

20. Alten RE, Zerbini C, Jeka S, et al. Efficacy and safety of pamapimod in patients with active rheumatoid arthritis receiving stable methotrexate therapy. Ann Rheum Dis 2010;69:364-7.
21. Machold KP, Landewé R, Smolen JS, et al. The Stop Arthritis Very Early (SAVE) trial, an international multicentre, randomised, double-blind, placebo-controlled trial on glucocorticoids in very early arthritis. Ann Rheum Dis 2010;69:495-502.

22. Schoels M, Knevel R, Aletaha D, et al. Evidence for treating rheumatoid arthritis to target: results of a systematic literature search. Ann Rheum Dis 2010;69:638-43.

23. Smolen JS, Aletaha D, Bijlsma JW, et al.; T2T Expert Committee. Treating rheumatoid arthritis to target: recommendations of an international task force. Ann Rheum Dis 2010;69:631-7.

24. Burr ML, Naseem H, Hinks A, et al.; BIRAC Consortium; YEAR Consortium. PADI4 genotype is not associated with rheumatoid arthritis in a large UK Caucasian population. Ann Rheum Dis 2010;69:666-70.

25. Emery $\mathbf{P}$, Durez P, Dougados $\mathrm{M}$, et al. Impact of T-cell costimulation modulation in patients with undifferentiated inflammatory arthritis or very early rheumatoid arthritis: a clinical and imaging study of abatacept (the ADJUST trial). Ann Rheum Dis 2010;69:510-16.

26. Bennett AN, Rehman A, Hensor EM, et al. The fatty Romanus lesion: a noninflammatory spinal MRI lesion specific for axial spondyloarthropathy. Ann Rheum Dis 2010;69:891-4.

27. Nam JL, Winthrop KL, van Vollenhoven RF, et al. Current evidence for the management of rheumatoid arthritis with biological disease-modifying antirheumatic drugs: a systematic literature review informing the EULAR recommendations for the management of RA. Ann Rheum Dis 2010;69:976-86.

28. Smolen JS, Landewé R, Breedveld FC, et al. EULAR recommendations for the management of rheumatoid arthritis with synthetic and biological disease-modifying antirheumatic drugs. Ann Rheum Dis 2010;69:964-75.

29. Tan RJ, Gibbons LJ, Potter C, et al.; BRAGGSS. Investigation of rheumatoid arthritis susceptibility genes identifies association of AFF3 and CD226 variants with response to anti-tumour necrosis factor treatment. Ann Rheum Dis 2010;69:1029-35.

30. Robinson JI, Barrett JH, Taylor JC, et al.; YEAR Consortium; BRAGGSS. Dissection of the FCGR3A association with RA: increased association in men and with autoantibody positive disease. Ann Rheum Dis 2010;69:1054-7.

31. Cohen SB, Keystone E, Genovese MC, et al. Continued inhibition of structural damage over 2 years in patients with rheumatoid arthritis treated with rituximab in combination with methotrexate. Ann Rheum Dis 2010;69:1158-61.

32. Haugeberg G, Bennett AN, McGonagle D, et al. Bone loss in very early inflammatory back pain in undifferentiated spondyloarthropathy: a 1-year observational study. Ann Rheum Dis 2010;69:1364-6.

33. Schoels M, Aletaha D, Smolen JS, et al. Follow-up standards and treatment targets in rheumatoid arthritis: results of a questionnaire at the EULAR 2008. Ann Rheum Dis 2010;69:575-8

34. Eyre S, Flynn E, Martin P, et al. No evidence for association of the KLF12 gene with rheumatoid arthritis in a large UK cohort. Ann Rheum Dis 2010;69:1407-8.

35. Eyre S, Hinks A, Flynn E, et al. Confirmation of association of the REL locus with rheumatoid arthritis susceptibility in the UK population. Ann Rheum Dis 2010;69:1572-3

36. Orozco G, Eyre S, Hinks A, et al.; Wellcome Trust Case Control consortium YEAR Consortium. Association of CD40 with rheumatoid arthritis confirmed in a large UK case-control study. Ann Rheum Dis 2010;69:813-16.

37. Emery $\mathbf{P}$, Durez P, Dougados $M$, et al. Impact of T-cell costimulation modulation in patients with undifferentiated inflammatory arthritis or very early rheumatoid arthritis: a clinical and imaging study of abatacept (the ADJUST trial). Ann Rheum Dis 2010;69:510-16

38. Saleem B, Keen $\mathrm{H}$, Goeb V, et al. Patients with RA in remission on TNF blockers: when and in whom can TNF blocker therapy be stopped? Ann Rheum Dis 2010;69:1636-42.

39. Barkham N, Coates LC, Keen H, et al. Double-blind placebo-controlled trial of etanercept in the prevention of work disability in ankylosing spondylitis. Ann Rheum Dis 2010;69:1926-8.

40. Emery P, Deodhar A, Rigby WF, et al. Efficacy and safety of different doses and retreatment of rituximab: a randomised, placebo-controlled trial in patients who are biological naive with active rheumatoid arthritis and an inadequate response to methotrexate (Study Evaluating Rituximab's Efficacy in MTX iNadequate rEsponders (SERENE)). Ann Rheum Dis 2010;69:1629-35.

41. Dixon WG, Hyrich KL, Watson KD, et al.; BSRBR Control Centre Consortium; British Society for Rheumatology Biologics Register. Influence of anti-TNF therapy on mortality in patients with rheumatoid arthritis-associated interstitial lung disease: results from the British Society for Rheumatology Biologics Register. Ann Rheum Dis 2010;69:1086-91. 